\title{
'Optimum mobility' facelift. Part 1 - the theory
}

\author{
Nabil Fanous MD FRCSC
}

N Fanous. 'Optimum mobility' facelift. Part 1 - the theory. Can J Plast Surg 2006;14(2):67-73.

Traditional rhytidectomy techniques, such as the cutaneous lift, the superficial musculoaponeurotic system lift, the deep plane lift and the subperiosteal lift, are mostly differentiated by their different planes of dissection. As well, many of these techniques consider the complete mobilization of tissues a prerequisite for obtaining a satisfactory result.

However, is it true that the result of a rhytidectomy is linked to the choice of the dissection plane? Also, is it true that the adequacy of the surgical mobilization of tissues is vital to the outcome? The present paper discusses the above questions and introduces a factor that is believed to be crucial to the planning and success of a rhytidectomy: facial tissue mobility. The analysis of this mobility is presented and leads to the development of three theories: 'intrinsic mobility', 'surgically induced mobility' and 'optimum mobility points'. These theories form the foundation of a rhytidectomy technique termed 'optimum mobility' facelift.

Key Words: Facelift; Optimum mobility; rhytidectomy

\section{Lifting du visage à « mobilité optimale »- Partie 1 : Théorie}

Les techniques classiques de rhytidectomie, comme le redrapage cutané, le redrapage du système musculo-aponévrotique superficiel, le redrapage du plan profond et le redrapage subpériostal se distinguent surtout par leurs plans de dissection. De même, nombre de ces techniques considèrent que la mobilisation complète des tissus est un préalable pour l'obtention de résultats satisfaisants.

Or, est-il vrai que le résultat de la rhytidectomie est lié au choix du plan de dissection? Et, la mobilisation chirurgicale des tissus est-elle vitale au pronostic? Le présent article aborde ces questions et met en lumière un facteur jugé indispensable à la planification et à la réussite de la rhytidectomie : la mobilité des tissus faciaux. On fait ici une analyse de la mobilité des tissus faciaux, qui se trouve à l'origine de trois théories : « mobilité intrinsèque », « mobilité induite chirurgicalement » et « points de mobilité optimale ». Ces théories forment la base d'une technique de rhytidectomie appelée lifting du visage à « mobilité optimale ».
$\mathrm{T}_{\mathrm{a}}^{\mathrm{h}} \mathrm{anc}$ he six primary goals of an ideal rhytidectomy are to achieve adequate tissue mobilization, to secure maximal and durable results, to entail minimal risks, to be followed by a speedy recovery, to be performed within a reasonable time and to be executed with an acceptable degree of technical complexity.

Numerous techniques of facial rejuvenation, striving to achieve these six goals, have appeared in the medical literature (1-38). A number of these techniques are simple to perform, have a low complication rate and portray minimal postoperative swelling, but their results may be limited or short-lived. Others have satisfactory results, but may be too complicated technically, may be followed by extensive postoperative edema or may carry higher than average risks. The large number of published facelifting techniques, old and new, testify to the constant, challenging and elusive search for an approach that is simple, safe and efficient.

\section{TRADITIONAL RHYTIDECTOMY CONCEPTS}

It is interesting to note that, traditionally, the various facelift techniques are mostly differentiated and compared by their different dissection planes. The current classification of facelift categories include: the subcutaneous lift; the subcutaneous lift with superficial musculoaponeurotic system (SMAS) manipulation; the sub-SMAS lift (deep plane lift, composite lift); the subperiosteal lift; and any combination of the above.

It is interesting to notice as well that most of these facelift approaches share the belief that adequate surgical mobilization of facial tissues, in the form of moderate to major dissection, displacement and redraping of these tissues, is paramount in delivering a superior rhytidectomy result.

In other words, the identification and success of a rhytidectomy have been generally linked to the choice of the plane of dissection and the adequacy of the surgical mobilization of tissues.

There is no doubt that the chosen plane of dissection is one of the main factors affecting the outcome of the different facelifting techniques, as proven clinically by the different results achieved. However, is the plane of dissection the major factor affecting a rhytidectomy result? And is the surgical mobilization of tissues another crucial factor?

The goal of the present study is to analyze these two questions and suggest an answer.

\section{INTRODUCTION}

\section{So easy to do with one finger, so hard to do with} major surgery

The following is a familiar story to most plastic surgeons: a middle-aged woman comes for a consultation regarding a 
facelift. She looks in the mirror, places one or two fingers on the side of her face and moves them a few centimetres in a superolateral direction. The result of this simple minimal manipulation is impressive, being equal or even superior to a good facelift outcome. The patient rightly comments, 'doctor, all I want is just this!'.

Reflecting on the above situation, two logical questions come to mind:

\section{- The first question}

How can two fingers placed merely $2.5 \mathrm{~cm}$ to $5 \mathrm{~cm}$ (1 in to 2 in) anterior to the ear crease and so far away from the midline achieve such a dramatic effect on the cheek, jowl and nasolabial fold? How can two fingers, placed externally on the skin obtain, without any dissection and with a negligible force, such a remarkable facial improvement that most facelift techniques struggle to achieve, even with the help of moderate to massive dissection, aggressive mobilization of tissues, superficial, deep or subperiosteal plane techniques, use of anchoring sutures, use of supporting screws, use of tissue glue, release of retaining ligaments, etc.

There is one possible explanation: the ability of that finger manoeuvre to displace facial tissues in a superolateral direction can be possible only through the use of a form of internal intrinsic mobility (gliding of tissues).

In other words, intrinsic mobility is a range of movement that exists naturally within the facial soft tissue planes before any surgical intervention. This intrinsic mobility is different from the acquired mobility induced by surgical dissection.

In part 1 of the present study (the theory), the 'intrinsic mobility' of facial planes is analyzed.

\section{- The second question}

If we can obtain such a dramatic result with two fingers and no dissection, why can we not do the same or even better with a limited surgery?

In part 2 of the present study (the technique), the 'optimum mobility' facelift technique will be discussed (pages 75-87).

\section{PART 1: THE THEORY - ANALYSIS OF FACIAL TISSUE MOBILITY}

\section{Anatomical review}

Since the description of the SMAS by Mitz and Peyronie in 1976 (39), great interest has been focused on further exploring the SMAS and incorporating it with rhytidectomy.

Numerous publications on the subject have attempted to study the anatomical details of the SMAS and its relationship to the different overlying and underlying facial planes (2,21,39-62). Classical anatomists described four different layers $(55,57-60,62)$ between the skin surface and the deep fascia of the face and neck: the skin (epidermis and dermis), the subcutaneous tissue (subcutis or panniculus adiposus), the fascia superficialis (or SMAS in most studies) and the subaponeurotic plane (or sub-SMAS space).

In the subcutaneous layer, the adipose tissue (fat lobules) is divided by multiple fibrous septae (retinacula cutis) running from the SMAS to the overlying dermis. These interlacing septae $(39,40,43,45,46,55,56)$ are often perpendicular to the skin (as in the cheek area), but are sometimes oblique or parallel

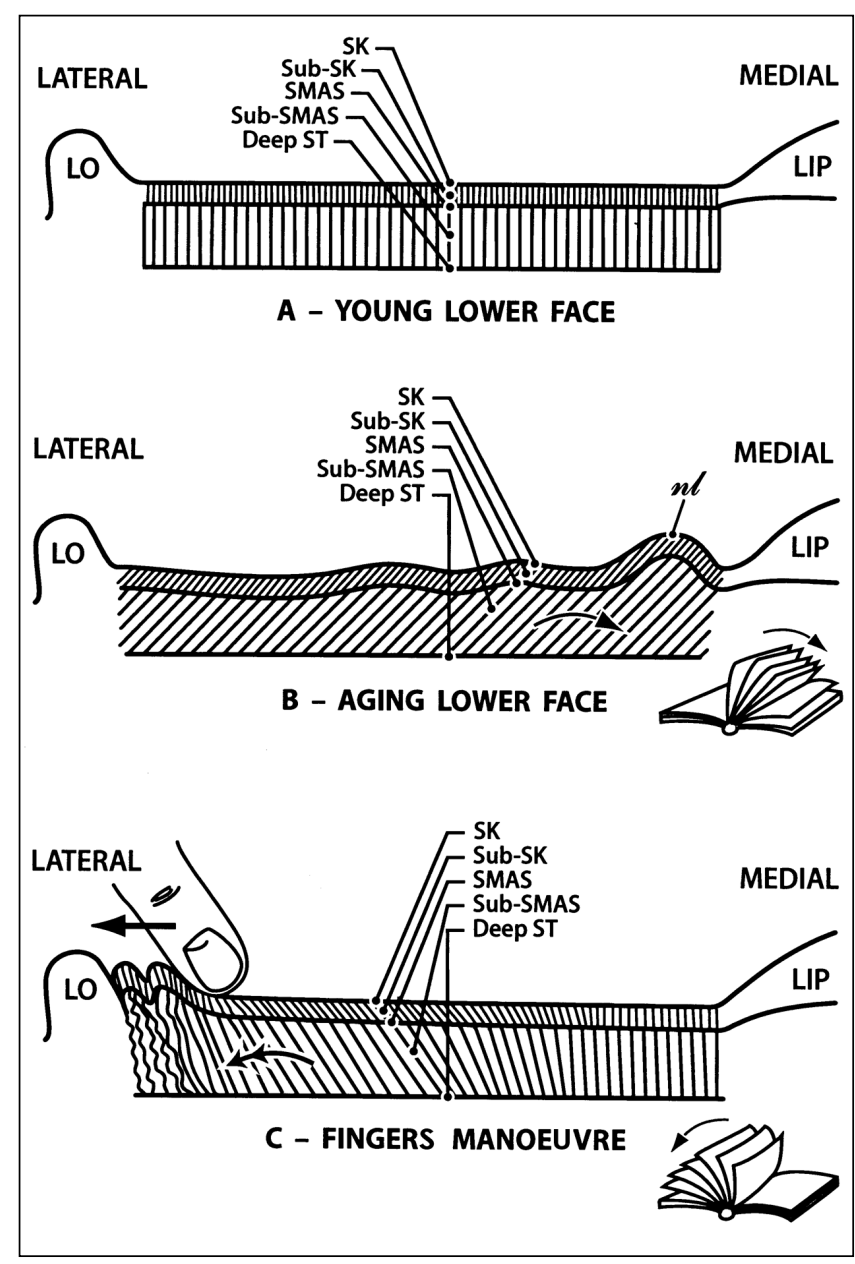

Figure 1) A The external soft tissue layers encountered in the young lower face, from superficial to deep: skin, subskin, superficial musculoaponeurotic system (SMAS) and sub-SMAS. Both sublayers contain a network of septae. B In the aging lower face, the skin and SMAS layers, as well as the septae in their corresponding sublayers, undergo elongation. The skin and SMAS gravitate (glide) medially toward the nasolabial folds (nl) (arrow). This 'intrinsic mobility' is due to the rotation of the septae in the two sublayers, from lateral to medial, much like the pages of an opened book, turning from one cover to the other. C This same 'intrinsic mobility' mechanism is used by the patient's fingers to mobilize the skin and SMAS laterally (in the opposite direction) (arrow). Deep ST Structures (deep muscles, periosteum); LO Lobule; SK Skin

to it (as in the parotid area). This fibroadipose organization of the subcutis is found in most of the face and neck regions. In the lips, however, the dermis is directly in contact with the orbicularis oris muscle, and the subcutaneous fat is minimal.

The superficial facial fascia (or SMAS) was described as a continuous fibromuscular sheath throughout the face and neck that lacks bony insertion (45). Since it was discovered by Mitz and Peyronie (39), it raised divided views among anatomists and surgeons in terms of histological and anatomical findings. Jost and Levet (44) described this fascia superficialis (SMAS) as one muscle that they called "the primitive platysma", with an upper part (parotid fascia) and a lower part (platysma). Wassef (55), Jost and Levet (44), and Levet (61) stated that this fibromuscular layer, which is the same as the superficial fascia, attaches anteriorly into the orbicularis oculi muscle, the zygomatic major muscle, the orbicularis oris muscle and the 
contralateral platysma; and laterally into the sternocleidomastoid muscle aponeurosis and the perichondrium of the tragal cartilage. The branches of the facial nerve lie deep to the SMAS.

The subaponeurotic space (or sub-SMAS space) separates the SMAS from the deep fascia of the face and neck. The most common type of separation is by an areolar plane. This areolar plane $(43-45,55,56)$, composed of a network of celluloadipose tissue, exists in areas such as the cheek (between the SMAS and the parotidomassetric fascia overlying the masseter muscle, and between the SMAS and the fat pad, or corpus adiposum buccae) and in the region of the neck (between the platysma and the underlying strap muscles).

\section{The facial soft tissue layers and the 'intrinsic mobility' theory}

Based on the above literature review, the external soft tissue layers encountered in the young lower face include two layers (skin and SMAS) and two sublayers (subskin and sub-SMAS) lying over the deep structures, in the following order, from superficial to deep (Figure 1A): skin (epidermis and dermis); subskin (subcutaneous layer); SMAS; and sub-SMAS, followed by the underlying deep structures (deep fascia, deep muscles and periosteum). The two sublayers (subskin and subSMAS) both contain a network of septae (trabeculae). In the case of the subskin layer, this network is made of dense fibrous septae $(39,40,43,45,46,55,56)$, mostly perpendicular to the skin, which connect it to the SMAS. In the case of the subSMAS layer, this network is composed of a much looser areolar tissue $(43-45,55,56)$ connecting the SMAS to the deep structures. In Figure 1A, for practicality and simplicity purposes, the septae of the subplanes are schematically represented by vertical lines to better demonstrate their dynamics.

In the aging lower face (Figure 1B), the skin and SMAS layers, as well as the septae in their corresponding sublayers, undergo redundancy and elongation, the same changes suffered by other body soft tissue secondary to the aging process. However, the underlying deep structures (eg, deep fascia, deep muscles and periosteum) remain almost undisplaced through aging. Because of this elongation of the skin and SMAS, and especially because of the accompanying elongation of the septae in their sublayers, the skin and SMAS gravitate medially and inferiorly toward the nasolabial fold (Figure $1 \mathrm{~B}-n l)$. Such a displacement of skin and SMAS is likely due to their gliding over their respective sublayers, because the sublayers are the only planes where significant side-to-side movement can take place. This gliding probably occurs through the rotation of the elongated septae (Figure 1B), with most of the movement of these septae happening at their superficial ends (where they attach to the skin or SMAS), rather than at their deep ones (at the fixed deep structures, in the case of the sub-SMAS plane).

In other words, the aging septae in the two sublayers (Figure 1B) seem to rotate with gravity from superolateral (or lateral for simplicity) to inferomedial (or medial for simplicity), much like the free borders of the pages of an opened book, turning from one cover to the other, while the opposite borders of these pages are still fixed at the binding (Figure 1B). The skin and SMAS are theoretically sitting on the free borders of these septae, and hence may be made to move medially (by gravity, Figure $1 \mathrm{~B}$ ) or laterally (by the fingers manoeuvre, Figure 1C).

Therefore, in the aging face (Figure 1B), gravity induces a gliding displacement by rotation of the septae medially. This rotation eventually comes to a stop once the fibrous septae have

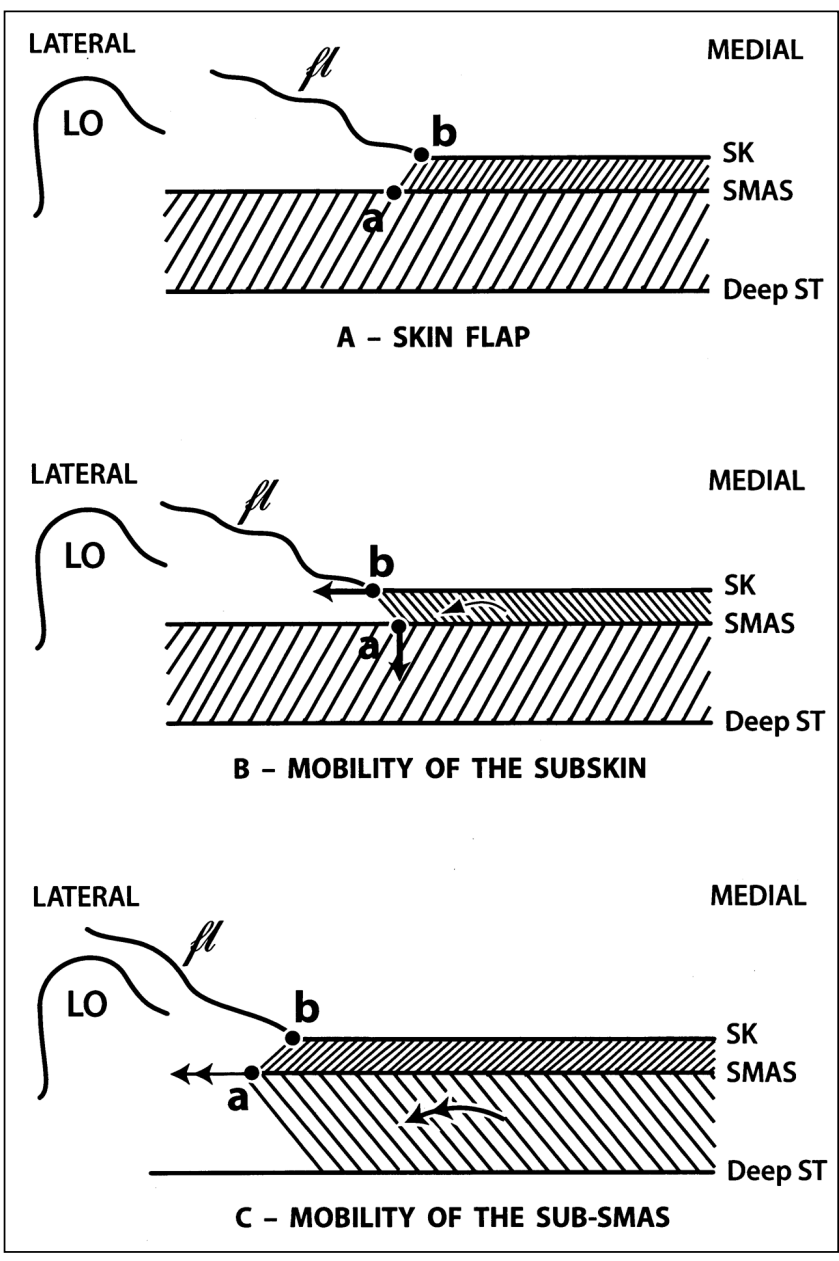

Figure 2) A test to prove the theory of 'intrinsic mobility' in the two sublayers. A During a regular facelift, a preauricular short skin flap (fl) is raised $2.5 \mathrm{~cm}$ to $5 \mathrm{~cm}$ ( 1 in to $2 \mathrm{in}$ ). B Checking intrinsic mobility in the subskin layer. The superficial musculoaponeurotic system (SMAS) is grasped with forceps at the medial end of the dissection (point a) and is fixed in place by downward pressure. Another forceps grasps the deep surface of the flap at the medial end of the dissection (b) and pulls it laterally. This manipulation shows a limited displacement of skin over SMAS (curved arrow), which confirms the limited intrinsic mobility in the subskin layer. C Checking intrinsic mobility in the sub-SMAS layer. The forceps catching the SMAS at point a is moved in a lateral direction. This mobilization of SMAS over deep structures (curved arrows) corresponds to the intrinsic mobility in the sub-SMAS layer, and is always found to be more significant than the mobilization previously obtained in the subskin layer. Deep ST Structures (deep muscles, periosteum); LO Lobule; SK Skin

fully rotated and are fully stretched. As well, it is this same intrinsic mobility elicited by gravity that is used by the patient's fingers (Figure 1C) to mobilize the planes in the opposite lateral direction. This lateral mobilization will also come to a halt once the fibrous septae have fully rotated and are fully stretched.

\section{Proving the theory of 'intrinsic mobility' in the}

\section{sublayers}

To test the validity of the above theory and prove which of the two sublayers (subskin or sub-SMAS) contributes more to the intrinsic mobility of the lower face, a simple test was initially performed by the author and could be tried by any surgeon (Figure 2). 
In the course of a regular facelift procedure, the preliminary subcutaneous dissection (Figure 2A) for $2.5 \mathrm{~cm}$ to $5 \mathrm{~cm}$ (1 in to $2 \mathrm{in}$ ) in front of the auricle is performed as usual to raise a short skin flap (Figure 2A - $f l$ ).

The first part of the test (Figure 2B) is to check the intrinsic mobility in the subskin plane. Using an Adson forceps, the SMAS is grasped at the medial end of the dissection (Figure 2Bpoint a), where the SMAS is still attached to the skin. The closed forceps is pushed down firmly to fix the SMAS at this point and to prevent it from moving. Then, using another Adson forceps (Figure 2B - point b), the deep surface of the skin flap, at the medial end of the dissection, is grasped at point $b$, just superficial to the other forceps holding down the SMAS at point $\mathrm{a}$. Therefore, both points $\mathrm{a}$ and $\mathrm{b}$ are separated only by the subskin layer. The skin forceps at point $b$ is then moved laterally to check how much can the undissected skin (at point b) be mobilized laterally over the SMAS (at point a). This mobility could happen only within the subskin layer between the skin and SMAS (rotation of septae between points a and b). This manipulation usually shows a limited displacement of skin over SMAS (point b moves only a little laterally past point a), which confirms the limited intrinsic mobility in the subskin layer.

The second part of this test (Figure 2C) is to check the mobility in the sub-SMAS layer. This is simply performed by moving the deep Adson forceps catching the undissected SMAS at point a in a lateral direction (SMAS moving over deep structures). This mobilization corresponds with the intrinsic mobility in the sub-SMAS layer, and is always found to be much more significant than the mobilization previously obtained in the subskin layer.

From the above test, one can conclude that intrinsic mobility is happening mainly in the sub-SMAS layer, and less so in the subskin layer.

\section{'Surgically induced' mobility of the lower face}

As explained, intrinsic mobility has limitations. The displacement of the skin and SMAS layers is partially controlled by the fibrous septae in the subplanes. In other words, the skin and SMAS are held captive, to a certain extent, by the underlying or overlying septae and are not allowed to move or stretch beyond a certain limit.

This principle is proven every time one attempts to close a moderate skin defect (eg, $2 \mathrm{~cm}$ [0.8 in] in diameter) anywhere in the body. If one tries to approximate the skin borders of this defect without subcutaneous dissection beyond these borders (in other words, by using only intrinsic mobility in the subskin and sub-SMAS layers), one will face a resistance because these borders can move only as much as the intrinsic mobility (the rotation and stretching of the septae in the two sublayers) will allow them. However, if one then dissects a centimetre or two of skin around the defect, the new skin flap will now be liberated from the underlying fibrous septae and will be free to further stretch, thereby, increasing in surface area and allowing the defect to be closed.

In other words, surgical dissection (flap dissection) under the skin or SMAS layers leads to a surgically induced mobility by liberating the skin, the SMAS or both from the underlying or overlying septae. As well, these skin and SMAS flaps will continue to stretch when subjected to further pulling force, and will therefore become somewhat thinner and weaker. In other words, the more one dissects under skin or SMAS in a facelift procedure, the more one distends and weakens the resultant skin and SMAS flaps.

Paradoxically, while the aims of a rhytidectomy are to tighten and strengthen the facial tissues by resecting and shortening them, the dissection used for mobilization creates, at the same time, the minimal but still contradictory effect of distending and weakening these flaps.

\section{Analysis of the finger manoeuvre}

Going back to the facelift patient showing her surgeon, with a finger or two, the result she anticipates, three possible scenarios can be analyzed using the anatomical and mechanical theories described earlier.

In the first scenario, suppose the patient puts her two fingers only $1 \mathrm{~cm}$ [0.4 in] in front of the lobule of her auricle and pulls laterally and superiorly. As she starts pulling, both skin and SMAS will move laterally, and the septae in both sublayers will turn from medial to lateral (Figure 3A), like the pages of an opened book. The septae that are just beneath the fingers rotate first, followed by the ones medial to them, and so on, until the septae that turned first (the ones under the fingers) are fully stretched. At this point, the pulling fingers will feel a resistance. Intrinsic mobility in both sublayers has come to a halt because the most lateral septae are now fully rotated and stretched, while the more medial septae are less so. Trying to apply more pulling force with the fingers will have little effect because those lateralmost septae, which are fibrous and fully stretched, will block further skin and SMAS advancement.

The 'fingers manoeuvre' in the above example produces a considerable tightening in the lateral cheek area close to the fingers, but has little impact on the faraway nasolabial fold (Figure $3 \mathrm{~A}-n l$ ).

In the second scenario, suppose now the patient advances her fingers to $2 \mathrm{~cm}(0.8 \mathrm{in})$ in front of her lobule and pulls laterally. The same dynamics will still apply. However, in this case, the rotation of septae will occur more medially on the face; therefore, the tightening effect will be more apparent on the nasolabial fold (Figure $3 \mathrm{~B}-n l$ ).

In the final scenario, suppose the surgeon decides to perform the fingers manoeuvre on the patient, repeating it a few times at $1 \mathrm{~cm}(0.4 \mathrm{in})$, then at $2 \mathrm{~cm}(0.8 \mathrm{in})$, then at $3 \mathrm{~cm}$ (1.2 in), etc, in front of the patient's lobule, each time pulling laterally and superiorly, and each time watching the effect on the nasolabial fold. The surgeon will notice a marked increase in the tightening effect on the nasolabial fold with every $1 \mathrm{~cm}$ advancement, until the fingers reach a certain point called the 'optimum mobility point', located usually between $2.5 \mathrm{~cm}$ to $5 \mathrm{~cm}$ ( 1 in to 2 in) in front of the lobule, after which the increase in the tightening effect on the nasolabial fold starts dropping dramatically with every additional advancement of the fingers (Figure 3C).

Therefore, the 'optimum mobility point' is the point at which one can obtain the most possible tightening at the centre of the face with the pulling fingers, while at the same time trying to have these fingers placed at the shortest possible distance from the lobule.

In other words, the 'optimum mobility point' is the 'point of diminishing return', meaning that if one goes with their fingers more medially beyond this point, one will commit themselves to more skin dissection during the facelift procedure, while getting negligible improvement on the nasolabial folds in return. The distance between the lobule and the 'optimum mobility 


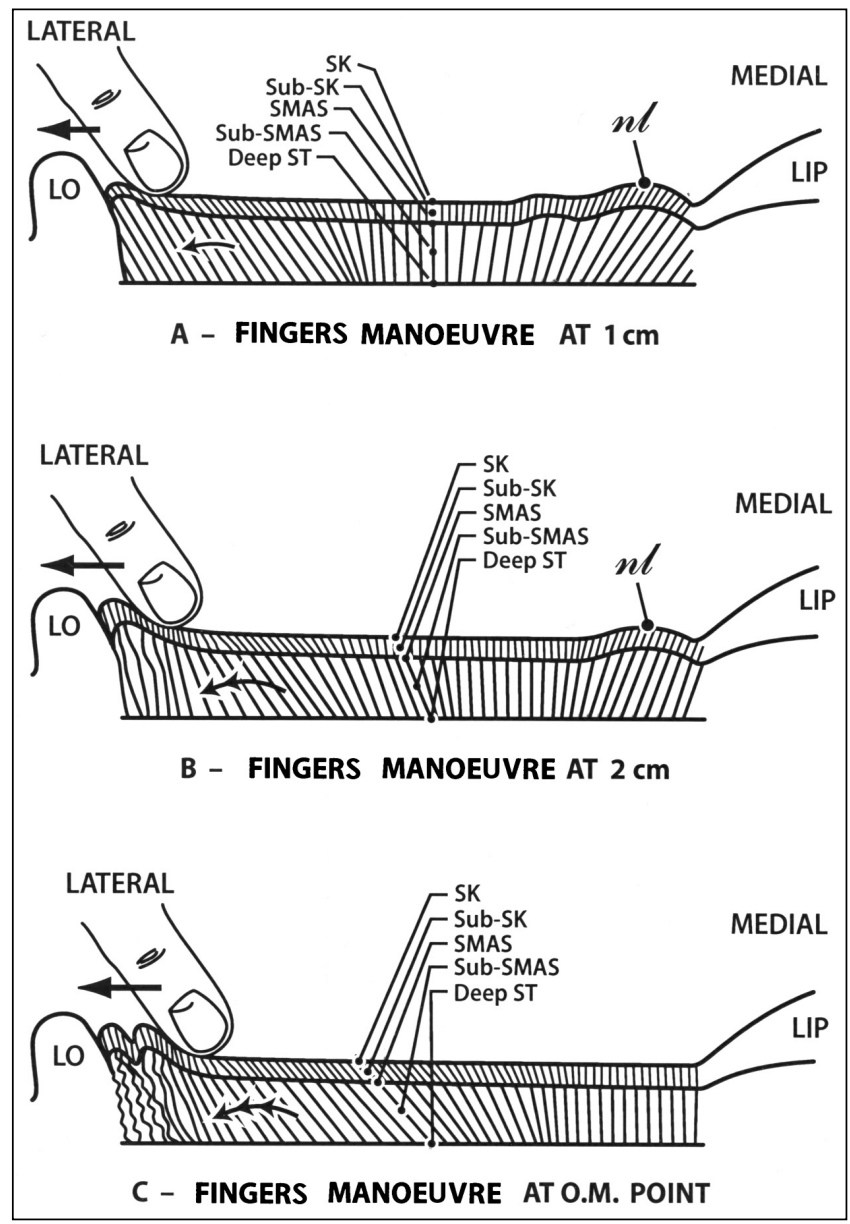

Figure 3) Analysis of the fingers manoeuvre. A Fingers manoeuvre (arrow) at $1 \mathrm{~cm}(0.4 \mathrm{in})$ in front of the lobule, having little impact on the nasolabial fold (nl). B The manoeuvre (arrow) is repeated at $2 \mathrm{~cm}$ (0.8 in) in front of the lobule, with a more apparent tightening effect on the nasolabial fold. C Fingers manoeuvre (arrow) at the 'optimum mobility (OM) point', located $2.5 \mathrm{~cm}$ to $5 \mathrm{~cm}$ (1 in to 2 in) in front of the lobule, causing the most possible tightening at the centre of the face, while at the same time having the fingers placed as close to the lobule as possible. Deep ST Structures (deep muscles, periosteum); LO Lobule; SK Skin; SMAS Superficial musculoaponeurotic system

point' is important because it will be used in the future as an indicator for the extent of subcutaneous dissection during the 'optimum mobility' facelift technique. One of the main goals of this technique is to use the minimal possible dissection, while producing the maximal possible effect on the central face. This is because the more one dissects, the more negative side effects one may create: more weakening and distension of tissues, more possibility of intraoperative bleeding, more intraoperative edema, more dead space left at the end of the procedure, more chances of future facial tissue stretch-back, more postoperative edema and more likelihood of postoperative hemorrhage.

\section{Addendum: Intrinsic mobility of the upper face and neck}

In the upper face of a young individual (Figure 4A), the anatomy is similar to that of the lower face, except for a thicker, fatter

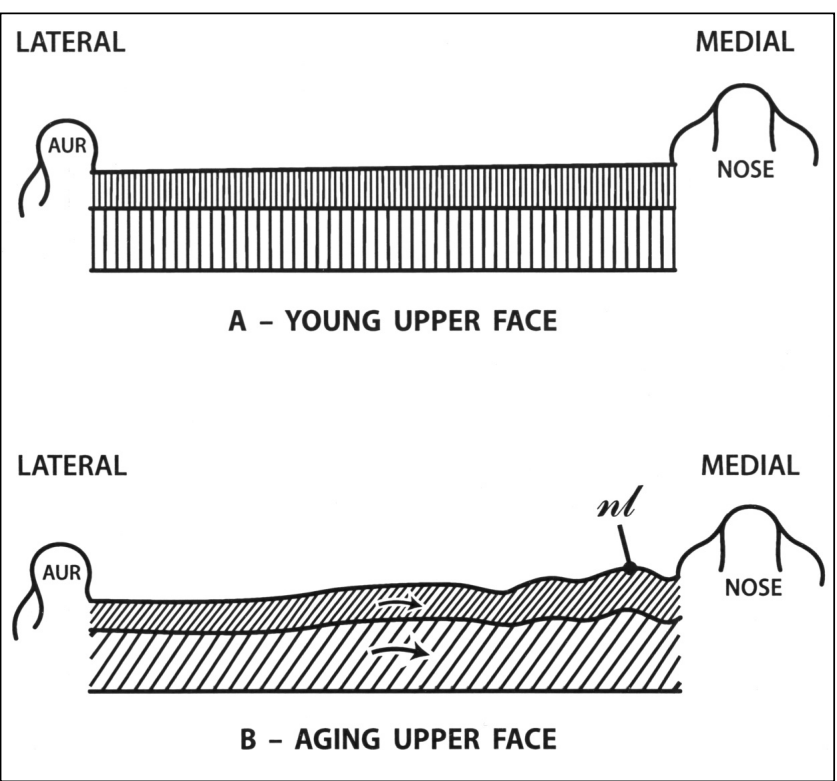

Figure 4) The external soft tissue layers encountered in the young upper face. A The subskin layer is thicker and fatter, having longer septae than in the young lower face (Figure 1A). B In the aging upper face, the long septae in the subskin layer produce more intrinsic mobility (gravitation) within that layer (large arrow), when compared with the subskin layer (small arrow) of the aging lower face (Figure 1B). AUR Auricle; nl Nasolabial fold

subskin layer at the level of the cheeks. Theoretically, this entails longer septae in the subskin plane and, therefore, more rotation and gliding potential within it (Figure 4B). This difference in anatomy will lead to a difference between the facelift techniques used in the lower and upper face, as will be discussed in part 2 (pages 75-87).

In the neck of a young individual, the soft tissues anatomy is very similar to that of the lower face. The only exception is the area of the posterior neck, behind the sternocleidomastoid muscle, where the skin attaches directly to the deep muscle fascia rather than to the SMAS, leading to a very limited intrinsic mobility in that area.

\section{CONCLUSIONS OF THE THEORY SECTION}

As discussed in the present article, there are three theories/mechanisms that form the foundation of the 'optimum mobility' facelift technique.

- 'Intrinsic mobility' allows the facial external soft tissue layers, mainly the skin and SMAS, to be mobilized by gravity or manipulation, without surgical dissection. It mainly happens through the gliding of the skin and SMAS over their respective sublayers (subskin, and especially sub-SMAS).

- 'Surgically induced mobility' allows the external facial soft tissue layers, mainly the skin and SMAS, to further stretch and advance as a result of surgical dissection. This is made possible by breaking the 
fibrous septae in one or both sublayers (subskin and sub-SMAS). The skin, SMAS or both are then liberated from the restraining septae and are free to spread further, leading not only to an increase in their displacement and their surface area (flap length), but also to a decrease in their strength and their resistance to the pulling force.

Thus, surgical dissection is a bit of a two-edged sword; on the one hand, it allows the surgeon to add mobility to a skin flap or a SMAS flap, while on the other hand, it slightly increases the length of that same flap. Therefore, the more dissection one does, the more extra length (though limited) one adds to the dissected flaps, and the more one has to overresect a little these flaps to neutralize their surgically induced elongation.

- 'Optimum mobility points' are points at which the pulling finger, using 'intrinsic mobility', can achieve the maximum possible tightening at the centre of the face or neck, while using the minimum possible advancement of that finger away from the lobule (for

\section{REFERENCES}

1. Tipton JB. Should the subcutaneous tissue be plicated in a face lift? Plast Reconst Surg 1974;54:1-5.

2. Owsley JQ Jr. Platysma-fascial rhytidectomy: A preliminary report. Plast Reconstr Surg 1977;60:843-50.

3. Jost G, Lamouche G. SMAS in rhytidectomy. Aesthetic Plast Surg 1982;6:69-74.

4. Webster RC, Smith RC, Smith KF. Face lift, Part 3: Plication of the superficial musculoaponeurotic system. Head Neck Surg 1983;6:696-701.

5. Webster RC, Smith RC, Papsidero MJ, Karolow WW, Smith KF. Comparison of SMAS plication with SMAS imbrication in face lifting. Laryngoscope 1982;92:901-12.

6. Abramo AC, Oliveira VE. The "lazy S-shaped" plication of the SMAS-platysma musculoaponeurotic system: A 10-year review. Aesthetic Plast Surg 2000;24:433-9.

7. Cardenas-Camarena L, Gonzalez LE. Multiple, combined plications of the SMAS-platysma complex: Breaking down the face-aging vectors. Plast Reconstr Surg 1999;104:1093-100.

8. Robbins LB, Brothers DB, Marshall DM. Anterior SMAS plication for the treatment of prominent nasomandibular folds and restoration of normal cheek contour. Plast Reconstr Surg 1995;96:1279-87.

9. Hamra ST. The zygorbicular dissection in composite rhytidectomy: An ideal midface plane. Plast Reconstr Surg 1998;102:1646-57.

10. Hamra ST. The deep-plane rhytidectomy. Plast Reconstr Surg 1990;86:53-61.

11. Hamra ST. The aging face: Analysis, surgical approach, and results assessment. Aesthetic Surg J 1996:65.

12. Hamra ST. Composite rhytidectomy. Plast Reconstr Surg 1992;90:1-13.

13. Hamra ST. Composite Rhytidectomy. St Louis: Quality Medical Publishing, 1993.

14. Krastinova-Lolov D. Mask lift and facial aesthetic sculpturing. Plast Reconstr Surg 1995;95:21-36.

15. Hinderer UT, Urriolagoitia F, Vildosola R. The blepharoperiorbitoplasty: Anatomical basis. Ann Plast Surg 1987;18:437-53.

16. Furnas DW. Festoons of orbicularis muscle as a cause of baggy eyelids. Plast Reconstr Surg 1978;61:540-6.

17. Adamson PA, Tropper GJ, McGraw BL. Extended blepharoplasty. Arch Otolaryngol Head Neck Surg 1991;117:606-9.

18. Hamra ST. Repositioning the orbicularis oculi muscle in the composite rhytidectomy. Plast Reconstr Surg 1992;90:14-22.

19. Fogli AL. Orbicularis muscleplasty and face lift: A better orbital contour. Plast Reconstr Surg 1995;96:1560-70.

20. Mendelson BC. Correction of the nasolabial fold: Extended SMAS dissection with periosteal fixation. Plast Reconstr Surg 1992;89:822-33. the lower face) or the hairline (for the upper face and neck). The idea of 'optimum mobility points' is to use the minimal possible skin dissection to achieve the maximal possible mobilization and effect on the central face because the less unnecessary dissection is performed, the better.

'Optimum mobility' points are therefore the 'points of diminishing return' because continuing to advance with the pulling finger medially beyond these points means more future skin dissection, but with less and less improvement on the central face or neck in return.

The clinical application of the 'optimum mobility points' will be fully explained in part 2, the technique section (pages 75-87).

ACKNOWLEDGEMENTS: The author thanks Ildico Horvath, medical artist, Montreal General Hospital (Montreal, Quebec), for her assistance in preparing the artwork; Barbara Armbruster MA for editing; Amanda Fanous for the literature search; Stephanie Luetticken MBA for organizing the manuscript; and Joelle Bejjani for typing.

21. Skoog T. Plastic Surgery: New Methods and Refinements. Philadelphia: WB Saunders, 1974.

22. Lemmon ML, Hamra ST. Skoog rhytidectomy: A five-year experience with 577 patients. Plast Reconstr Surg 1980;65:283-97.

23. Baker DC. Minimal incision rhytidectomy (short scar face lift) with lateral SMASectomy: Evolution and application. Aesthetic Surg J 2001;21:14-26.

24. Saylan Z. The S-lift: Less is more. Aesthetic Surg J 1999;19:406.

25. Finger ER. A 5-year study of the transmalar subperiosteal midface lift with minimal skin and superficial musculoaponeurotic system dissection: A durable, natural-appearing lift with less surgery and recovery time. Plast Reconstr Surg 2001;107:1273-83.

26. Hobar PC, Flood J. Subperiosteal rejuvenation of the midface and periorbital area: A simplified approach. Plast Reconstr Surg 1999;104:842-51.

27. Tessier P. Mask lift. The SOFCEP. Paris, September 17, 1988.

28. Psillakis JM. Craniofacial methods in rhytidoplasty. The Aesthetic Surgery Symposium. Rio de Janeiro, 1982.

29. Psillakis JM, Rumley TO, Camargos A. Subperiosteal approach as an improved concept for correction of the aging face. Plast Reconstr Surg 1982;82:383-94.

30. Krastinova-Lolov D. Le lifting facial sous-perioste. Ann Chir Plast Esthet 1989;34:199-211.

31. Ramirez OM, Maillard GF, Musolas A. The extended subperiosteal facelift: A definitive soft-tissue remodeling for facial rejuvenation. Plast Reconstr Surg 1991;88:27-36.

32. Ramirez OM. Classification of facial rejuvenation techniques based on the subperiosteal approach and ancillary procedures. Plast Reconstr Surg 1996;97:45-55.

33. Ramirez OM. The subperiosteal approach for the correction of the deep nasolabial fold and the central third of the face. Clin Plast Surg 1995;22:341-56.

34. Ortiz-Monasterio F. Subperiosteal face-lifting. The First European Association of Plastic Surgery Congress. Strasbourg, June 9, 1990.

35. Hester TR, Codner MA, McCord CD. The centrofacial approach for the correction of facial aging using the transblepharoplasty subperiosteal cheek lift. Aesthetic Surg J 1996;16:51-8.

36. Maloney BP, Schiebelhoffer J. Minimal-incision endoscopic facelift. Arch Facial Plast Surg 2000;2:274-8.

37. Mendelson BC. Correction of the nasolabial fold: Extended SMAS dissection with periosteal fixation. Plast Reconstr Surg 1992;89:822-33.

38. Fredricks S. Radical face lift surgery: A plea for caution. Aesthetic Surg J 2002;22:86.

39. Mitz V, Peyronie M. The superficial musculo-aponeurotic system (SMAS) in the parotid and cheek area. Plast Reconstr Surg 1976;58:80-8. 
40. Gosain AK, Yousif NJ, Madiedo G, Larson DL, Matloub HS, Sanger JR. Surgical anatomy of the SMAS: A reinvestigation. Plast Reconstr Surg 1993;92:1254-63.

41. Rees TD, Aston SJ. A clinical evaluation of the results of submusculo-aponeurotic dissection and fixation in face lifts. Plast Reconstr Surg 1977;60:851-9.

42. Owsley JQ Jr. SMAS-platysma face lift. Plast Reconstr Surg 1983;71:573-6.

43. Thaller SR, Kim S, Patterson H, Wildman M, Daniller A. The submuscular aponeurotic system (SMAS): A histologic and comparative anatomy evaluation. Plast Reconstr Surg 1990;86:690-6.

44. Jost G, Levet Y. Parotid fascia and face lifting: A critical evaluation of the SMAS concept. Plast Reconstr Surg 1984;74:42-51.

45. Stuzin JM, Baker TJ, Gordon HL. The relationship of the superficial and deep facial fascias: Relevance to rhytidectomy and aging. Plast Reconstr Surg 1992;89:441-9.

46. Ghassemi A, Prescher A, Riediger D, Axer H. Anatomy of the SMAS revisited. Aesthetic Plast Surg 2003;27:258-64.

47. Gonzalez-Ulozm M. The history of rhytidectomy. Aesthetic Plast Surg 1980;4:1.

48. Lassus C. Cervicofacial rhytidectomy: The superficial plane. Aesthetic Plast Surg 1997;21:25-31.

49. Connell BF, Marten TJ. The trifurcated SMAS flap: Three-part segmentation of the conventional flap for improved results in the midface, cheek, and neck. Aesthetic Plast Surg 1995;19:415-20.

50. Guerrerosantos J. Rhytidoplasty: Improving cheek and neck with simplified and refined surgical technique. In: Russell RC, ed.
Instructional Courses: Plastic Surgery Educational Foundation, vol 4. St Louis: Mosby Year Book, 1991:27.

51. Lewis JR. Multiple-tiered deep support of cheeks in meloplasty and rhytidectomy. Aesthetic Plast Surg 1983;7:21-5.

52. Owsley JG. In: McCarthy JG, ed. Aesthetic Facial Surgery. Philadelphia: WB Saunders, 1994.

53. Stuzin JM, Baker TJ, Gordon HL. The extended SMAS flap in the treatment of the nasolabial fold. The Annual Meeting of the American Society for Aesthetic Plastic Surgery. Chicago, 1990.

54. Bosse JP, Papillon J. Surgical anatomy of the SMAS at the malar region. In: Transactions of the 9th International Congress of Plastic and Reconstructive Surgery. New York: McGraw-Hill, 1987:348.

55. Wassef M. Superficial facial and muscular layers in the face and neck: A histological study. Aesthetic Plast Surg 1987;11:171-6.

56. Ruess W, Owsley JQ. The anatomy of the skin and fascial layers of the face in aesthetic surgery. Clin Plast Surg 1987;14:677-82.

57. Warwick R, Williams P, eds. Gray's Anatomy of the Human Body, 35th edn. Philadelphia: Saunders, 1973.

58. Poirier P, Charpy A, eds. Traité d'anatomie humaine. Paris: Masson et $\mathrm{Cie}, 1912$.

59. Rouvière H. Anatomie humaine, descriptive, topographique et fonctionnelle. Paris: Masson, 1974.

60. Testut L, Letrajet A. Traité d'anatomie humaine. Paris: Doin, 1949.

61. Levet Y. Discussion of surgical anatomy of the SMAS: A reinvestigation. Plast Reconstr Surg 1993;92:1264.

62. Har-Shai Y, Bodner S, Egozy-Golan D, et al. Mechanical properties and microstructure of the superficial musculoaponeurotic system. Plast Reconstr Surg 1996;98:59-70. 